\title{
STUDI EMPIRIS TERKAIT DENGAN PENGUNGKAPAN SUKARELA, KUALITAS AUDIT DAN ASIMETRI INFORMASI TERHADAP STOCK RETURN PADA PERUSAHAAN MANUFAKTUR YANG TERDAFTAR PADA BURSA EFEK INDONESIA
}

\author{
Jenny Sihombing, Sukrisno Agoes dan Urip Santoso \\ Universitas Katolik Parahyangan dan Pengajar pada Universitas Advent Indonesia- \\ Bandung, Universitas Tarumanagara, Universitas Katolik Parahyangan, Bandung \\ E-mail address: sihombingjenny@gmail.com
}

\begin{abstract}
This study used data of manufacturing companies listed on the Jakarta Stock Exchange (JSX) as unit of analysis. The purpose of this study is to find out the influence of voluntary disclosures and audit quality on information asymmetry. This study also aims to determine the effect of voluntary disclosure, audit quality and information asymmetry on stock return. In addition, this study aims to find out the ability of information asymmetry to mediate the effect of voluntary disclosure and audit quality on information asymmetry. This research used verificative-descriptive method with quantitative approach. The analytical method used in statistical data processing was path analysis. There are 132 manufacturing companies listed on JSX became the research samples of this study.The testing results shows that there are significant impact of voluntary disclosure and audit quality on information asymmetry. The testing results also show that there are significant impact of voluntary disclosure and information asymmetry on stock return, while the audit quality has no significant impact on stock return. At the same time, information asymmetry is significant to be the mediating variable on the impact of voluntary disclosure and audit quality towards stock return. Voluntary disclosure, audit quality and information asymmetry can be the determinant variables on Stock Return of manufacturing companies, listed on JSX.
\end{abstract}

Keywords: voluntary disclosure, audit quality, information asymmetry, stock return.

Abstrak: Penelitian ini menggunakan data perusahaan manufaktur yang terdaftar di Bursa Efek Jakarta (BEJ) sebagai unit analisis. Tujuan dari penelitian ini adalah untuk mengetahui pengaruh pengungkapan sukarela dan kualitas audit pada asimetri informasi. Penelitian ini juga bertujuan untuk mengetahui pengaruh pengungkapan sukarela, kualitas audit dan asimetri informasi terhadap return saham. Selain itu, penelitian ini bertujuan untuk mengetahui kemampuan asimetri informasi untuk menengahi efek pengungkapan sukarela dan kualitas audit pada penelitian asymmetry.This informasi menggunakan metode verifikatif-deskriptif dengan pendekatan kuantitatif. Metode analisis yang digunakan dalam pengolahan data statistik adalah analisis jalur. Ada 132 perusahaan manufaktur yang terdaftar di BEJ menjadi sampel penelitian study.The ini menguji hasil menunjukkan bahwa ada dampak signifikan dari sukarela pengungkapan dan kualitas audit pada asimetri informasi. Hasil pengujian juga menunjukkan bahwa ada dampak signifikan dari pengungkapan sukarela dan asimetri informasi terhadap return saham, sedangkan kualitas audit tidak berpengaruh signifikan terhadap return saham. Pada saat yang sama, asimetri informasi adalah signifikan menjadi variabel mediasi tentang dampak sukarela pengungkapan dan kualitas audit terhadap return saham. Sukarela pengungkapan, kualitas 
audit dan asimetri informasi dapat menjadi variabel penentu pada Return Saham perusahaan manufaktur, yang terdaftar di BEJ.

Kata kunci: pengungkapan sukarela, kualitas audit, asimetri informasi, return saham.

\section{PENDAHULUAN}

Krisis keuangan telah menunjukkan pentingnya kontribusi dan peran pasar modal bagi perekonomian nasional (Otoritas Jasa Keuangan, 2014).Masalah transparansi informasi kepada publik juga menjadi salah satu faktor penyebab terjadinya krisis keuangan di Indonesia (Daniri, 2006).

Pasar modal Indonesia memiliki potensi peningkatan dan prospek yang cukup baik. Jumlah perusahaan yang tercatat di BEI pada akhir 2012 berjumlah 466, meningkat sebesar 16,5\% dari posisi di tahun 2007. Kapitalisasi pasarnya mencapai $45.18 \%$ dari Produk Domestik Bruto pada tahun 2012, dengan rata-rata dunia sebesar $73,92 \%$ (Otoritas Jasa Keuangan, 2014).

Jumlah kapitalisasi pasar yang besar dan cenderung meningkat dari tahun-ketahun menunjukkan bahwa pasar modal Indonesia memberikan peluang yang baik dan bahkan mengalami peningkatan bagi dunia investasi. Pertumbuhan kapitalisasi pasar tersebut juga diikuti dengan bertumbuhnya jumlah emiten yang terdaftar pada Bursa Efek Indonesia. Hal ini menandakan bahwa perusahaan memandang pasar saham menjadi alternatif pendanaan yang sangat potensial guna untuk melakukan ekspansi usaha kedepan.

Melihat begitu besarnya kesempatan berinvestasi pada saham, juga besarnya peluang sumber pendanaan bagi perusahaan yang go public, maka perlu pengawasan dan regulasi yang baik, agar praktik transaksi pada pasar saham menjadi lebih sehat. Pengawasan dan penetapan regulasi yang tepat dimaksudkan untuk menjadi jaminan bagi para investor saham bahwa setiap uang yang diinvestasikan akan aman dan memberikan pengembalian yang sesuai dengan diharapkan. Lebih lanjut, dikatakan bahwa itu akan melindungi investasi yang dilakukan dan untuk meningkatkan kesejahteraan investor (Taplin et al., 2002).

Banyaknya skandal korporasi yang besar telah terjadi, seperti kasus Enron, WorldCom, Citigroup, Xerox dan yang lainnya, memberikan contoh tragis bagaimana kecuranganberdampak sangat buruk terhadap pasar modal. Salah satu upaya dan respons atas kasus-kasus tersebut maka diterbitkan undang-undang yang dikenal dengan SarbanesOxley Act dan disertai dengan aturan pelaksanaan pada pasar modal.

Ikatan Akuntan Indonesia, pada PSAK No.1, paragraf 7 menyatakan bahwa laporan keuangan bertujuan umum untuk memenuhi kebutuhan bersama sebagian besar pengguna laporan keuangan. Lebih lanjut, paragraf 9 menyatakan bahwa tujuan laporan keuangan disajikan untukmemberikan informasi mengenai posisi keuangan, kinerja keuangan dan arus kas yang bermanfaat bagi sebagian besar kalangan pengguna dalam pengambilan keputusan ekonomi. Laporan keuangan sebagai media dan bentuk pertanggungjawaban untuk mengungkapkan informasi yang bermanfaat bagi pihak-pihak yang berkepentingan sebagai pengguna informasi dalam mengambil keputusan ekonomi(Ikatan Akuntan Indonesia, 2013).

Peraturan OJK terkait, termasuk dalam peraturan perundang-undangan di sektor pasar modal yang mengatur mengenai penyajian dan pengungkapan informasi bagi perusahaan terbuka.Informasi mengenai data keuangan perusahaan saja belum cukup, 
sehingga perusahaan perlu menyikapinya dengan menyajikan informasi pendukung dalam bentuk lain, yaitu annual report(Otoritas Jasa Keuangan, SE.No. 32 /SEOJK.04/2015).

Transparansi dalam annual report menyangkut pengungkapan informasi tentang suatu keadaan seperti apa adanya. Ada dua sifat pengungkapan, yaitu pengungkapan yang didasarkan pada ketentuan atau standar (mandatory disclosure) dan pengungkapan yang bersifat sukarela (voluntary disclosure). Pengungkapan bersifat sukarela dilaksanakan perusahaan dimana butir-butirpengungkapan yang dilakukan secara sukarela tanpa diharuskan oleh peraturan yang berlaku. Standar akuntansi tidak mewajibkan pengungkapan yang maksimal, tetapi tidak menghalangi manajemen untuk memberikan tambahan pengungkapan informasi secara sukarela. Pertimbangan manajemen dalam kebijakannya untuk mengungkapkan informasi secara sukarela umumnya dipengaruhi oleh faktor biaya dan manfaat (Gregory et al., 2004).

Umumnya perusahaan sangat hati-hati dalam mengungkapkan informasi perusahaan. Hal ini dilakukan karena manajemen mengkhawatirkan kemungkinan efek respon negatif pengambilan keputusan oleh pengguna informasi atas pengungkapan informasi keuangan yang detail. Lebih lanjut dikatakan bahwa pengungkapan tidak cukup dipenuhi secara minimum saja. Kualitas pengungkapan menjadi perhatian yang penting, karenanya perlu ada upaya agar manajemen menyampaikan informasi yang relevan dan berkualitas baik kepada para pemangku kepentingan lainnya untuk dapat menurunkan asimetri informasi. Pengungkapan sukarela tentang keadaan sesungguhnya, serta proyeksi perusahaan kedepan menjadi perhatian penting agar secara efektif dapat menurunkan asimetri informasi antara manajemen dengan pemegang saham (Brown and Hillegeist, 2007).

Informasi sebagi produk dari pengungkapan selanjutnya digunakan menjadi alat bantu dalam mengambil keputusan. Pada tingkat informasi yang tinggi sebagai hasil pengungkapan yang baik, maka para investor dan calon investor semakin yakin dengan keputusan investasi yang mereka buat. Keadaan demikian juga akan meningkatkan kualitas keputusan, volume perdagangan investasi semakin tinggi karena permintaan yang tinggi dan berdampak pada peningkatan harga dan peningkatan return saham.

Sekalipun hasil studi telah menunjukkan hubungan negatif pengungkapan dengan asimetri informasi dan selanjutnya berdampak pada kinerja saham dan respon harga, namun tingkat pengungkapan di Indonesia masih belum cukup baik diterapkan. Hasil studi menunjukkan bahwa tingkat pengungkapan dariperusahaan sampel perusahaan yang diteliti di Indonesia masih berada pada posisi yang rendah (Darmadi, 2013). Hasil studi lain dari Gregory et al., menunjukkan bahwa ternyata pengungkapan secara penuh sampai pengungkapan sukarela banyak dilakukan perusahaaan hanya sekedarnya saja (Gregory et al., 2004).

Bersamaan dengan meningkatnya jumlah perusahaan go public, maka kebutuhan akan audit laporan keuangan oleh kantor akuntan publik juga mengalami peningkatan. Kualitas informasi pada hasil laporan auditor merupakan hal yang diperhatikan dalam peningkatan harga saham perusahaan. Kualitas audit menjadi penting karena dengan kualitas audit yang baik maka informasi yang dihasilkan melalui laporan keuangan juga mengandung jaminan kewajaran yang layak.

Penerapan kualitas corporate governance yang baik akan memberikan pengaruh positif pada pengungkapan yang akan menurunkan tingkat asimetri informasi (Silveira and Barros, 2006). Upaya penerapan corporate governance yang baik termasuk juga melalui transparansi keadaan perusahaan yang sebenarnya dan pelaporan keuangan perusahaan sesuai dengan standar pelaporan yang ditetapkan. Dikatakan lebih lanjut bahwa kualitas 
audit yang lebih baik bisa mengurangi ketidakpastian dan mengurangi noise dalam pelaporan keuangan (Balsam, 2002).

Investor yang telah berpengalaman melakukan investasi di pasar selalu mencari informasi mengenai perusahaan yang sahamnya akan dibeli sebelum melakukan investasinya. Annual report adalah sarana informasi antara pengguna informasi dengan manajemen perusahaan. Pengguna informasi meminta pengungkapan annual report yang transparan dan lengkap guna menunjang pengambilan keputusan bisnis yang optimal. Semakin banyak dan relevannya informasi yang diperoleh oleh investor dan calon investor, maka tingkat keyakinan berinvestasi semakin tinggi. Kondisi seperti ini disebut dengan pasar yang efisien dimana terjadi simetris informasi antara manajemen dengan para pihak investor dan atau calon investor (Manurung, 2013).

Lebih lanjut Manurung berpendapat, adanya asimetri informasibisa membuat investor mengalami kerugian atau negativestock return, sehingga regulator meminta perusahaan yang terdaftar dibursa untuk selalu transparan. Manajemen perusahaan diminta untuk mengumumkan semua informasi yang ada agar tidak ada yang dirugikan (Manurung, 2013).

Perusahaan manufaktur sebagai cabang industri memanfaatkan mesin, peralatan, tenaga kerja dan lainnya untuk mengubah barang mentah menjadi barang setengah jadi atau barang jadi untuk dijual. Perusahaan manufaktur yang go publicdi Indonesiajumlahnya lebih banyak dibandingkan dengan perusahaan dagang maupun jasa, sehingga memiliki pengaruh cukup besar dalam pembangunan perekonomian Indonesia (Indonesian Capital Market Electronic Library-ICAMEL, http://www.idx.co.id/enus/home/ aboutus/idxprogram/educationalprogram.aspx, dikunjungi pada 24 September 2016, 21:05 wib).

Hingga September 2016, perusahaan pada industri manufaktur menurut klasifikasi yang ada di Bursa Efek Indonesia terdiri dari tiga sektor industri yaitu sektor industri dasar dan kimia, sektor industri barang konsumsi dan sektor aneka industri. Perusahaan pada industri ini memiliki 20 sub sektor, jumlah perusahaan pada sektor manufaktur adalah 148 perusahaan dari 522 perusahaan yang terdaftar pada Bursa Efek Indonesia. Catatan tersebut menunjukkan bahwa perusahaan pada sektor ini merupakan sektor yang terbesar bila dibandingkan dengan sektor yang ada lainnya, atau berkisar 28\% dari jumlah perusahaan yang terdaftar pada Bursa Efek Indonesia (ICAMEL dikunjungi dari http://www.idx.co.id/en-us/home/listedcompanies/listedcompany calendar.aspx, dikunjungi pada 24 September 2016, at 21:18 wib). Itulah sebabnya peneliti memilih industri manufaktur sebagai target perusahaan yang diteliti.

Penelitian Bernardi berhasil membuktikan ada pengaruh negatif antara luasnya pengungkapan terhadap asimetri informasi (Bernardi, 2009). Pada kesempatan lain Nakhodchari dan Garkaz tidak menemukan korelasi antara pengungkapan dengan asimetri informasi pada perusahaan yang terdaftar di Tehran stock exchange (Nakhodchari dan Garkaz, 2014).

Fenomena yang terjadi adalah, aturan tentang pengungkapan telah dibuat dan hasil studi telah menunjukkan bahwa pengungkapan yang baik memberikan return saham yang baik. Kenyataan yang terjadi bahwa tingkat pengungkapan yang dilakukan di Indonesia masih sekedar saja (Darmadi, 2013).

Audit report yang dihasilkan oleh eksternal auditor diharapkan dapat meningkatkan keyakinan para investor dan penggunaan informasi keuangan untuk miningkatkan public trust. Kualitas audit serta pemahaman penggunaan informasi 
keuangan perusahaan yang telah diaudit dengan benar menjadi salah satu kunci penting untuk peningkatan kualitas informasi perusahaan termasuk bagi para investor. Kualitas informasi seperti ini sangat dibutuhkan dalam upaya meningkatkan kayakinan mereka sebagai pengguna informasi tetap tinggi (Murphy, 2014).

Fenomena lain adalah bahwa kualitas audit yang baik akan meningkatkan kepastian informasi keuangan perusahaan, mengurangi noise dan akan memberikan manfaat yang menguntungkan bagi auditor dan auditee. Kenyataan yang terjadi bahwa masih sangat perlu peningkatan kualitas audit pada negara-negara ASEAN, termasuk Indonesia (Favere-Marchesi, 2000).

Fenomena berikutnya yang ditemukan bahwa seharusnya tidak terjadi asimetri informasi antara manajemen dengan pemegang saham perusahaan atau calon investor di pasar modal. Kenyataan yang terjadi bahwa para calon investor saham dan pedagang saham di pasar modal tidak banyak menggunakan informasi yang dikeluarkan manajemen melalui pengungkapan dalam keputusan investasi mereka. Pasar modal di Indonesia masih terjadi herding, keputusan beli dan jual para investor berdasarkan ikut-ikutan keputusan beli-jual para pelaku pasar sebelumnya. Salah satu sebab terjadinya herding ini adalah masih rendahnya kualitas informasi yang ada di publik (Ramli et al., 2016).

Berdasarkan latar belakang penelitian dan uraian tersebut di atas, maka penulis melakukan penelitian ini dengan tujuan untuk mengetahui bagaimana pengaruh pengungkapan sukarela dan kualitas audit terhadap asimetri informasi. Bagaimana pengaruh pengungkapan sukarela, kualitas audit dan asimetri informasiterhadap stock return. Penelitian ini juga bertujuan untuk mencari tahu jawaban atas apakah asimetri informasi dapat menjadi variabel pemediasi atas pengaruh pengungkapan sukarela dan kualitas audit terhadap stock return.

Hubungan Antara Pengungkapan Sukarela dengan Kualitas Audit. Keadaan sistem ekonomi yang terbuka pada masa sekarang ini membuat permintaan akan kualitas informasi semakin tinggi. Para investor menginginkan informasi dengan kualitas dan kuantitas, serta kekinian informasi yang tinggi.Selain itu perusahaan yang ingin meningkatkan nilai perusahaannya dapat melakukannya dengan meningkatkan pengungkapan agar lebih baik kualitas dan jumlah informasi yang sampai kepada publik (Lobo and Zhou, 2001).

Audit atas laporan keuangan dengan tingkat kualitas yang baik akan meningkatkan sistem pengendalian yang baik, transparansi menjadi tinggi, sehingga akan menaikkan kepercayaan investor kepada perusahaan. Hal tersebut terjadi karena pengungkapan yang lebih baik terjadi di dalamnya. Tingkat kualitas audit yang baik seperti ini juga akan memberikan dampak peningkatan pelaksanaan corporate governance yang lebih baik (Griffin, et al., 2008; Muhamad et al., 2009).

Audit tenure adalah lama hubungan perikatan antara auditor dengan klien sebagai perusahaan yang diaudit secara secara berturut-turut.masa penugasan audit yang lebih lama tidak akan berdampak kepada independensi auditor. Auditor akan berusaha berkerja secara profesional dan akan lebih faham tentang pelaksanaan internal control dan level of corporate governance yang diterapkan perusahaan kliennya, sehingga input akan lebih baik diberikan. Hal tersebut berarti bahwa perikatan audit yang lebih panjang akan meningkatkan hasil audit yang lebih baik (Carey and Simnett, 2006), dengan demikian bahwa kualitas audit berkorelasi positif signifikan dengan kualitas pengungkapan informasi kepada publik (Nosheen, 2013). Keadaan tersebut akan meningkatkan 
pengungkapan dan memperluas informasi khusus bagi berbagai pihak, termasuk bagi investors (Dunn and Mayhew, 2004).

Pengaruh Pengungkapan Sukarela terhadap Asimetri Informasi. Manajemen memiliki tanggung jawab untuk memberikan informasi yang berkaitan tentang perusahaan kepada pengguna informasi terutama pemegang saham.Asimetri informasi digambarkan sebagai studi dalam pengambilan keputusan pada transaksi yang terjadi, dimana pada satu pihak memiliki lebih banyak atau lebih baik informasi yang dimiliki dibandingkan pada pihak yang lain. Keadaan asimetri informasi mengakibatkan banyak masalah pada para pelaku di pasar modal, termasuk kurangnya kuantitas atau kualitas informasi untuk pengambilan keputusan investasi (Nikolaou et al., 2013).

Cara pengungkapan mempengaruhi asimetri informasi adalah dengan mengubah perilaku perdagangan dari uninformed investors manjadi informed investors. Pada perusahaan dengan pengungkapan yang tinggi maka volume transaksi akan cenderung lebih meningkat (Fishman and Hagerty, 1989).

Semakin banyak informasi yang diungkapkan (melebihi pengungkapan yang diharuskan), maka akan mengurangi ketidakpastian informasi perusahaan. Demikian juga bahwa semakin kecil perkiraan risiko investasi karena informasi yang ada di pasar semakin lengkap dan berkualitas(Botosan and Plumlee, 2002). Kualitas pengungkapan secara keseluruhan perusahaan (termasuk financial dan non financial) berpengaruh negatif dengan tingkat asimetri informasi (Brown and Hillegeist, 2007; Ertimur, 2007; Buskirk, 2011; Gajewski and Li, 2015).

Pengaruh Kualitas Audit terhadap Asimetri Informasi. Keakuratan dan keandalan informasi keuangan menjadi perlu diperhatikan. Auditor independen diperlukan dalam rangka membantu dalam memberikan informasi yang dapat dipercaya tentang perusahaan.Independensi auditor dipandang sangat penting dalam upaya pengungkapan informasi yang sesungguhnya, relevan dan berkualitas, sehingga kualitas audit akan meningkat (Al-Thuneibat et al., 2010).

Lamanya perikatan audit antara auditor dengan kliennya (audit tenure) tidak selalu menurunkan tingkat independensi auditor eksternal dalam tugas perikatannya (Carey and Simnett, 2006).

Keberadaan auditor memberikan jaminan bagi investor bahwa laporan keuangan perusahaan sesuai dengan prinsip akuntansi yang berlaku umum. Auditor haruslah berusaha untuk menunjukkan bahwa laporan keuangan yang disajikan handal adanya, manajer berperilaku baik dan jujur, dan informasi tentang perusahaan yang tercermin ke publik adalah tepat adanya. Dengan demikian, asimetri informasi antara manajer dan investor menurun bilamana tingkat kualitas informasi keuangan meningkat(Leuz and Verrecchia, 2000).

Auditor memberikan dua peluang penting bagi pasar, yakni: pengetahuan dan jaminan. Hal ini dikarenakan auditor independen mengaudit dan memverifikasi laporan keuangan yang disusun oleh manajemen. Dengan cara ini, kualitas audit yang baik memberikan kontribusi untuk keandalan informasi yang diungkapkan (Muller and Riedl, 2002). Kualitas audit yang baik akan membantu mengurangi asimetri informasi antara pihak manajemen dengan dengan para pihak lain termasuk para investor (Dunn and Mayhew, 2004; Hakim and Omri, 2010; Clinch et al., 2012; Varici , 2013). 
Pengaruh Pengungkapan Sukarela terhadap Stock Return. Pengungkapanperusahaan merepresentasikan gambaran holistik informasi yang diberikan oleh perusahaan kepada pihak eksternal, yang meliputi informasi keuangan dan non-keuangan, kuantitatif atau kualitatif, mandatory atau voluntary (Von-Alberti et al., 2012). Banyak informasi yang dihasilkanakan mengurangi ketidakpastian informasi perusahaan dan future cash flowsjuga semakin memperkecil perkiraan risiko investasi. Kedaan ini akan meningkatkan volume transaksi dan harga saham dan meningkatkan stockreturn atasinvestasi yang dilakukan (Botosan and Plumlee, 2002).

Efektivitas aturan pengungkapan dan pengungkapan sukarela akan membuka informasi lebih baik tentang keterjadian perusahaan. Informasi yang terbuka seperti itu akan memberikan tanggapan positif dari pasar ketika informasi positif tentang perusahaan disampaikan sehingga mempengaruhi harga dan stock return (Haggard et al., 2008).

Pengungkapan penuh dalam pelaporan tahunan akan memberikan reaksi pasar yang lebih baik pada stock return (Goto et al., 2009). Informasi ke depan yang diungkapkan oleh perusahaan dengan reputasi tinggi, serta informasi penuh yang diungkapkan memiliki efek besar pada volatilitas stock return (Bravo, 2015).Ditemukan juga bahwa para investor institusi sangat merespon akan perubahan praktik pengungkapan yang dilakukan oleh perusahaan, terutama untuk pengungkapan yang bersifat sukarela (baik keuangan dan non keuangan). hal tersebut memberikan dampak positif pada volatilitas harga saham dan stock return (Venkatachalam, 2015).

Pengaruh Kualitas Audit terhadap Stock Return. Dalam pengambilan keputusan dibutuhkan informasi yang berkualitas. Tujuan penyajian laporan keuangan secara umum adalah untuk memenuhi kebutuhan informasi sebagian besar pengguna laporan (Ikatan Akuntan Indonesia, pada PSAK No.1, IAI, 2013). Pemahaman penggunaan informasi keuangan perusahaan yang telah diaudit menjadi salah satu kunci yang sangat penting dalam keputusan investasi. Kualitas informasi keuangan diyakini akan meningkat setelah dilakukan pemeriksaan oleh auditor. Dalam situasi krisiskeuangan sekalipun penggunaan informasi keuangan yang telah diaudit dalam upaya meningkatkan kayakinan pengguna informasi tetap tinggi (Murphy, 2014).

Publikasi informasi keuangan dalam bentuk informasi pendapatan yang diperoleh dalam suatu periode tertentu akan berpengaruh terhadap ekspektasi investor tentang kemampuan perusahaan untuk menghasilkan keuntungan dimasa depan. Hal tersebut akan tercermin dalam perubahan harga saham perusahaan yang bersangkutan dalam pasar modal. Dengan melihat bahwa nilai saham padaearning response coefficient dipengaruhi oleh kualitas laba yang dilaporkan perusahaan dan persepsi mengenai kualitas pendapatan, yang juga dapat dipengaruhi oleh public audit firms(Nuryaman, 2013).

Ditemukan juga bahwa kualitas audit yang lebih tinggi bisa mengurangi ketidakpastian dan mengurangi noise dalam pelaporan keuangan yang ditunjukkan oleh earning response coefficient yang tinggi (Balsam, 2002). Ditemukan juga bahwa terdapat pengaruh positif antara corporate governance (dimana kualitas audit sebagai salah satu dimensi) terhadap kinerja perusahaan. (Nuryaman, 2012).

Nuryaman juga mengatakan kualitas audit dapat memperkuat pengaruh negatif dari earnings management terhadap return saham (Nuryaman, 2013). Gul et al., menemukan bahwa jumlah informasi laba tercermin dalam stock return lebih rendah untuk perusahaan dengan sinkronisitas tinggi (Gul et al., 2010). Choi et al., lebih awal telah menemukan 
bahwa terdapat pengaruh yang signifikan dari kualitas audit terhadap stock return (Choi et al., 2008).

Pengaruh Asimetri Informasi terhadap Stock Return. Asimetri informasi adalahsuatu kondisi dimana terdapatnya satu pihak memilikiinformasilebih dibandingkan dengan pihak lain. Pada lingkungan pasar, makainiterjadi ketikapenjualmemilikiinformasilebih bila dibandingkan dengan pembeliatau sebaliknya. Keadaan ini tidakdisukai karenasalah satu pihak dapat memanfaatkan informasi yang tersedia baginya untuk mencapai manfaat tertentu atas biaya pihak lain yang memiliki informasilebih sedikit. Dalam beberapa kasus, asimetri informasi terjadi ketikasalah satu pihakmengeksploitasibeberapacelahdalam perjanjianatau kontrak, sementara pihak laintidak dapat melakukannya (Aboody andLev, 2000).

Penelitian yang mencari hubungan antara asimetri informasi dan stock return menemukan bahwa terdapat hubungan terbalik pada kedua variabel tersebut. Pada investasi diportofolio dengan asimetri informasiyang tinggiakan menghasilkan abnormal profits yang tinggi (Easley and O'Hara, 2004).

Pada saat asimetri informasi semakinrendah, didapati bahwa semakin tinggi harga saham untuk memprediksi kinerja akuntansi masa depan. Studi ini menemukan bahwa entitas dinegara yang menerapkan corporate governance yang lebih baik, yang ditandai dengantingkat asimetri informasi yang lebih rendah.Demikian juga bahwa entitasdi negara-negaradenganpasar yang lebih majujuga ditandai dengantingkat asimetri informasi yang lebih rendah(Gul and Qiu, 2002).

Hal penting yang perlu diperhatikan adalah terjadinya asimetri informasi yang tinggi ditandai dengan bid ask spread saham yang melebar, ini dikarenakan karena pasar memandang adanya risiko investasi yang tinggi. Asimetri informasi yang tinggi biasanya juga ditandai dengan volume transaksi pasar yang cenderung rendah karena permintaan yang rendah. Simetri informasi berdampak positif terhadap stock return, namun ketika kebijakan akuntansi konservatif yang dilakukan manajemen maka dampaknya akan memudar atau menghilang (Yassin et al., 2015). Kong et al., menemukan hal yang menyerupai itu, bahwa asimetri informasi memiliki dampak negatif signifikan pada sensitivitas investasi, harga saham dan selanjutnya terhadap stock return(Kong et al., 2011).

Berdasarkan uraian di atas, maka hipotesis penelitian ini adalah:

Hipotesis1: Pengungkapan sukarela dan kualitas audit berpengaruh signifikan terhadap asimetri informasi.

Hipotesis2 : Pengungkapan sukarela, kualitas audit dan asimetri informasi berpengaruh signifikan terhadap stock return.

Hipotesis3: Asimetri informasi dapat menjadi variabel pemediasi atas pengaruh dari pengungkapan sukarela dan kualitas audit terhadap stock return.

\section{METODE}

Konsep model penelitian disajikan pada gambar 1, yang dibangun berdasarkan telaah pustaka, kerangka pemikiran dan hasil temuan para peneliti terdahulu. Pada model terlihat bahwa hubungan dan bahkan pengaruh satu variabel dengan variabel yang lainnya dilandaskan atas teori-teori atau penelitian yang terdahulu. 


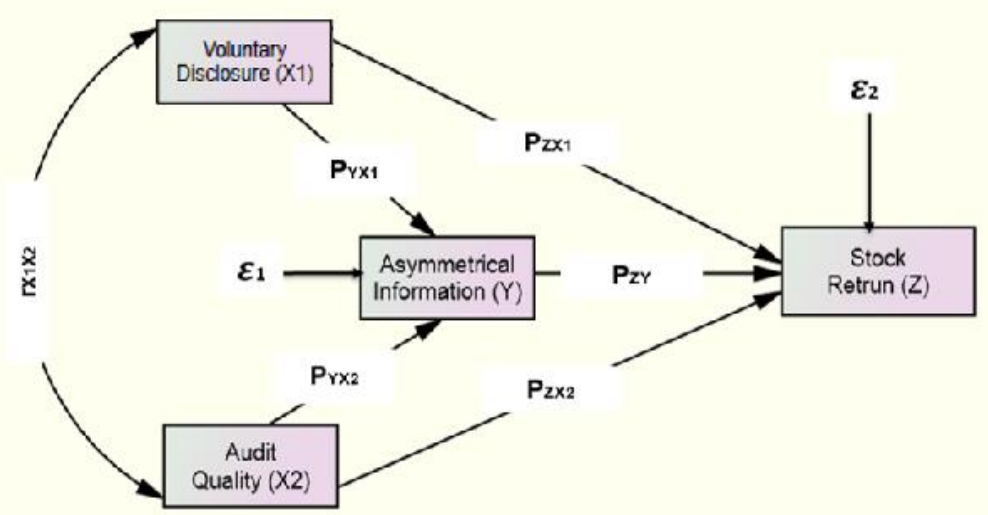

Keterangan:

Gambar 1.Model Penelitian

$\mathrm{rX}_{1} \mathrm{X}_{2}$ : Hubungan antara variabel $\mathrm{X}_{1}$ dengan variabel $\mathrm{X}_{2} ; \mathrm{PYX}_{1}$ : Koefisien jalur varaiabel $\mathrm{X}_{1}$ terhadap variabel $\mathrm{Y} ; \mathrm{PYX}_{2}$ : Koefisien jalur varaiabel $\mathrm{X}_{2}$ terhadap variabel $\mathrm{Y}$; $\mathrm{PZX}_{1}$ : Koefisien jalur varaiabelX $X_{1}$ terhadap variabel $\mathrm{Z} ; \mathrm{PZX}_{2}$ : Koefisien jalur varaiabelX $X_{2}$ terhadap variabel $\mathrm{Z}$; PZY : Koefisien jalur varaiabelY terhadap variabel Z; $\mathrm{X}_{1}$ : Pengungkapan sukarela; $\mathrm{X}_{2}$ : Kualitas audit; $\mathrm{Y}$ : Asimetri informasi; $\mathrm{Z}:$ Stock return; $\varepsilon_{1}$ : Faktor lain yang mempengaruhi asimetri informasi (epselon 1); $\varepsilon_{2}$ : Faktor lain yang mempengaruhi stock return(epselon 2).

Seluruh variabel penelitian ini memiliki skala rasio, dengan model path analysis framework, maka pengolahan data dilakukan dengan menggunakan Amos v. 21.0. Berdasarkan model path analysis yang dibangung maka persamaan model penelitian ini menjadi:

$$
\begin{aligned}
& \mathrm{Y}=\mathrm{P}_{\mathrm{YX} 1} \mathrm{X}_{1}+\mathrm{P}_{\mathrm{YX} 2} \mathrm{X}_{2}+\varepsilon_{1} \\
& \mathrm{Z}=\mathrm{P}_{\mathrm{ZX} 1} \mathrm{X}_{1}+\mathrm{P}_{\mathrm{ZX} 2} \mathrm{X}_{2}+\mathrm{P}_{\mathrm{ZY}} \mathrm{Y}+\varepsilon_{2}
\end{aligned}
$$

Penelitian ini menggunakan menggunakan verificative-descriptivedengan pendekatan kuantitatif dan pengujian hipotesis. Penelitian inimerupakan penelitian bisnis, yaknidengan melakukan pengorganisasian dan investigasi terhadap masalah tertentu secara terorganisir, sistematik, berbasisdata,kritis danobjektif,yang dilakukandengan tujuanuntuk menemukan solusiuntuk permasalahan yang ada (Sekaranand Bougie, 2010).

Berdasarkan struktur konseptual model yang telah dibangun dalam memprediksi stock return, maka metodologi penelitian ini diuraikan mencakup operasionalisasi variabeldan sampel penelitian.

Operasionalisasi Variabel. Pengukuran pengungkapan yang digunakan pada penelitian ini berdasarkan pengungkapan sukarela, mencakup unsur strategic information, key nonfinancial information, financial information dan projected information. Terdapat 49 items pengungkapan yang perlu dilakukan pengecekan pada setiap laporan tahunan perusahaan yang diamati (Ismail and El-Shaib, 2012). Pendekatan check list pengungkapan seperti ini telah dilakukan juga pada penelitian lain (Bruslerie andGabteni, 2010; Banghoj, 2008; Aljifri, 2008). Pengungkapan sukarela sebagai perwakilan variabel $\mathrm{X}_{1}$, diukur dengan rumus sebagai berikut:

$$
\text { Pengungkapan sukarela }(X 1)=\frac{\text { realisasi unsur pengungkapan dilakukan }}{\text { maximum unsur pengungkapan }} \times 100 \%
$$


Pengukuran kualitas audit dilakukan berdasarkan lamanya perikatan audit (dalam tahun) antara kantor akuntan publik dengan kliennya sebagai perusahaan yang diaudit secara berturut-turut (Attig et al., 2006). Perikatan audit yang lebih lama akan memberikan pemahaman auditor akan industri klien lebih baik dan akan memberikan masukan yang lebih baik bagi kliennya. Hal tersebut berarti bahwa perikatan audit yang lebih panjang akan meningkatkan kualitas audit dan peningkatan informasi kepada publik yang lebih baik (Carey and Simnett, 2006).Kualitas audit merupakan perwakilan dari variabel $\mathrm{X}_{2}$ penelitian ini.

Asimetri informasi dalam penelitian ini diukur berdasarkan besarnya rata-rata bidaskspread selama periode pengamatan. Asimetri informasi yang terjadi ditandai dengan semakin besarnya spread harga bid dengan ask pada pasar saham (Attig et al., 2006). Asimetri informasi merupakan perwakilan variabel $\mathrm{Y}$, diukur dengan dengan rumus sebagai berikut:

Realisasi bid-ask spread $=\sum_{n} \frac{\text { ask price }- \text { bid price }}{n}$

Dimana: $\mathrm{n}=$ jumlah hari pengamatan

Pengukuran stock return yang digunakan dalam penelitian adalah merupakan keseluruhan pengembalian atas investasi saham yang dilakukan, berupa capital gain -loss yield ditambah dengan dividenyield (Ross et al., 2015).Lebih lanjut, stock returnsebagai perwakilan variabel $\mathrm{Z}$, pengukuran stock returndilakukan berdasarkan total return dengan rumus:

\section{Total return $=$ capital gain $($ loss $)$ yield + dividen yield}

Sampel Penelitian. Sekaran dan Bougie mengatakan populasi adalah keseluruhan kelompok orang, kejadian, atau hal yang diminati dan ingin diinvestigasi oleh peneliti sedangkan sampel adalah sejumlah elemen populasi yang dipilih (Sekaran and Bougie, 2010).

Populasi penelitian ini adalah perusahaan manufaktur yang terdaftar di Bursa Efek Indonesia (BEI).Berdasarkan objek penelitian ini, maka sampel yang digunakan merupakan perusahaan industri manufaktur yang terdaftar di BEI, yang secara konsisten menerbitan laporan tahunannya sepanjang tahun pengamatan, tahun 2012-2014.

Terdapat 148 perusahaan pada industri manufaktur yang terdaftarpada BEI. Ada 16 perusahaan yang tidak termasuk dalam sampel, yakni 14 perusahaan baru listing dalam tahun pengamatan penelitian dan 2 perusahaan yang laporan tahunannya tidak lengkap atau rusak. Dari data tersebut maka didapati ada 132 perusahaan manufaktur yang menjadi sampel penelitian ini(Indonesian Capital Market Electronic Library-ICAMEL, http://www.idx.co.id/en-us/home/listedcompanies/announcement.aspx, dikunjungi pada 24 September 2016, 21:43 wib).

\section{HASIL DAN PEMBAHASAN}

Uji Kelayakan Data. Pada pengujian dengan path analysis mempunyai asumsi yang mendasari, yakni bahwa data haruslah bersifat normal dan juga linier (Riduwan and 
Kuncoro, 2011). Berdasarkan hal tersebut maka data dari penelitian ini terlebih dahulu diuji normalitas dan liniaritasnya.

Uji Normalitas Data

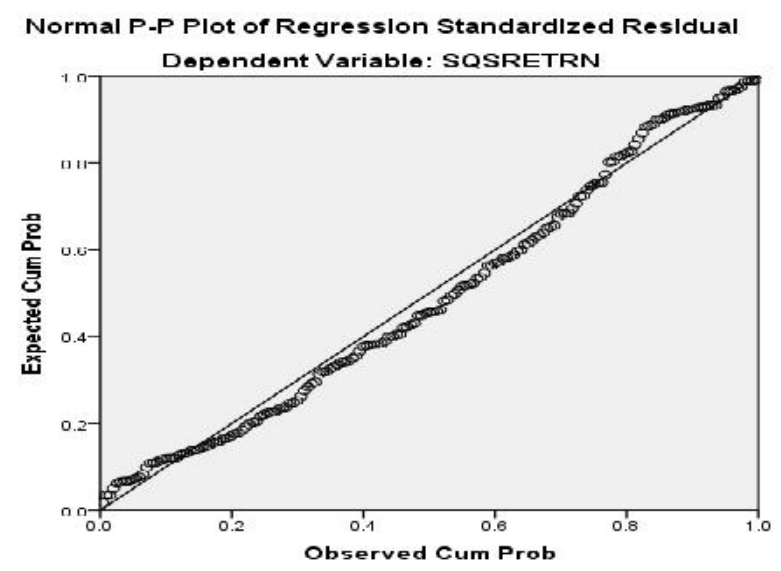

Gambar 2. Hasil Uji Normalitas Data

Gambar 2 hasil uji normalitas data (normal plot) menunjukkan bahwa data telah terdistribusi normal, dimana titik-titik menyebar dekat disekitar garis diagonal, ini menunjukkan bahwa data telah berdistribusi normal dan telah memenuhi syarat normalitas.

Uji Liniaritas Data. Uji linearitas bertujuan untuk melihat apakah spesifikasi model yang digunakan sudah benar atau tidak, atau apakah antar variabel memiliki hubungan linearitas yang baik atau tidak. Model yang baik, seharusnya memiliki hubungan linier antara variabel prediktor atau eksogen dengan variabel kriterium atau endogen (Ghozali, 2012).

Tabel 1. Ringkasan Tabel Anova untuk Uji Linearitas

\begin{tabular}{lrrrrr}
\hline \multicolumn{1}{c}{ Deviation from Linearity } & $\begin{array}{c}\text { Sum of } \\
\text { Squares }\end{array}$ & $d f$ & $\begin{array}{c}\text { Mean } \\
\text { Square }\end{array}$ & $F$ & Sig. \\
\hline Stock_retrn * Volunt_Discl & 705.056 & 73 & 9.658 & .993 & .509 \\
Stock_retrn * Audit_Qual & 90.562 & 4 & 22.640 & 2.219 & .069 \\
Stock_retrn* Asym_Inf & 1452.437 & 127 & 11.437 & 1.492 & .055 \\
\hline
\end{tabular}

Hasil output anova uji liniaritas data yang terdapat pada Tabel 1 menunjukkan bahwa nilai signifikansi masing-masing antar variabel adalah $>0,05$ (yakni uji pada $\alpha=$ 0,05). Berdasarkan hasil tersebut disimpulkan bahwa terdapat hubungan linier signifikan antara variabel eksogen dengan variabel endogen pada model penelitian ini. Dengan demikian maka syarat liniaritas data telah terpenuhi.

Pengaruh Pengungkapan Sukarela Dan Kualitas Audit Terhadap Asimetri Informasi. Berdasarkan hasil pengujian pada Tabel2 dapat dilihat bahwa pengungkapan sukarela yang lebih baik dan kualitas audit (dengan proxy audit tenur yang lebih lama) 
secara bersama mempengaruhi asimetri informasi. Pengaruh tersebut ditandai dengan kontribusi sebesar 3,5\% terhadap asimetri informasi, sementara faktor lain sebesar 96.5\% ditentukan oleh faktor-faktor lain (seperti kepemilikan perusahaan, komitmen manajemen, etc) diluar penelitian ini. Lebih lanjut hal tersebut digambarkan pada diagram jalur pada Gambar 3.

Tabel 2. Koefisien Jalur pada Sub Struktur Pertama

\begin{tabular}{cccccc}
\hline Path Direction & $\begin{array}{c}\text { Path } \\
\text { Coefficient }\end{array}$ & $t_{\text {count }}$ & $\begin{array}{c}t_{\text {table }} \\
(\text { db:322) }\end{array}$ & p-value & $\begin{array}{c}R \text { - } \\
\text { Square }\end{array}$ \\
\cline { 1 - 5 } Volunt_Discl $\rightarrow$ Asym_Inf & -0.147 & -2.697 & 1.967 & 0.007 & 0.032 \\
\cline { 1 - 5 } Audit_Qual $\rightarrow$ Asym_Inf & 0.119 & 2.177 & 1.967 & 0.029 & \\
\hline
\end{tabular}

Hal tersebut memberikan implikasi bahwaperluadanya pengawasan yang lebih baik agar pengungkapan yang dilakukan tidak sekedar memenuhi syarat yang diwajibkan, tetapi agar informasi yang disampaikan benar-benar bermanfaar bagi pengguna informasi. Hal serupa yang perlu diperhatikan sehingga kualitas audit juga dapat mendorong pengungkapan yang baik, yang merupakan cerminan keadaan keuangan perusahaan yang sesungguhnya. Upaya-upaya yang dilakukan melalui eksogen variabel penelitian ini diharapkan dapat menurunkan asimetri informasi antara manajemen dengan para pemangku kepentingan lainnya pada perusahaan manufaktur yang terdaftar di BEI.

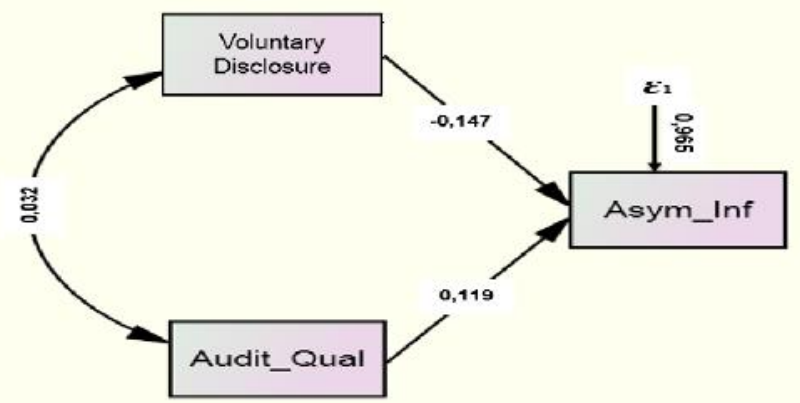

Gambar 3. Model Diagram Hipotesis 1: Pengaruh Pengungkapan Sukarela dan Kualitas Audit Terhadap Asimetri Informasi

Pengaruh Pengungkapan Sukarela Terhadap Asimetri Informasi. Hipotesis yang dibangun untuk ini adalah:

$$
\begin{array}{ll}
\mathrm{H}_{0}: \rho \mathrm{YX}_{1}=0 & \begin{array}{l}
\text { Pengungkapan sukarela tidak berpengaruh terhadap asimetri } \\
\text { informasi. }
\end{array} \\
\mathrm{H}_{\mathrm{a}}: \rho \mathrm{YX}_{1} \neq 0 & \begin{array}{l}
\text { Pengungkapan sukarela berpengaruh terhadap asimetri } \\
\text { informasi. }
\end{array}
\end{array}
$$

Berdasarkan hasil pengujian pada Tabel2 dapat dilihat nilai thitung pengungkapan sukarela terhadap asimetri informasi sebesar -2,690 dengan nilai koefisien jalur negatif, probability sebesar 0,007. Nilai negatif pada thitungmenunjukkan arah koefisien, yang sesuai dengan arah jalurnya. Hal tersebut menunjukkan bahwa nilai $t_{\text {hitung }}(2,690)>t_{t a b e l}$ $(1,967)$, pada $\alpha=5 \%$ diputuskan untuk menolak Ho dan menerima Ha. Berdasarkan hal tersebut dapat disimpulkan bahwa pengungkapan sukarela berpengaruh signifikan terhadap asimetri informasi. Dalam pengertian bahwa peningkatan pengungkapan sukarela akan menurunkan asimetri informasipada perusahaan manufaktur yang terdaftar di BEI. 
Pengaruh Kualitas Audit Terhadap Asimetri Informasi . Hipotesis yang dibangun untuk ini adalah:

$\mathrm{H}_{0}: \rho \mathrm{YX}_{2}=0 \quad$ Kualitas audit tidak berpengaruh terhadap asimetri informasi.

$\mathrm{H}_{\mathrm{a}}: \rho \mathrm{YX}_{2} \neq 0 \quad$ Kualitas audit berpengaruh terhadap asimetri informasi.

Berdasarkan hasil pengujian pada Tabel 2 dapat dilihat nilai thitung kualitas audit terhadap asimetri informasi sebesar 2,177 dengan nilai koefisien jalur positif, nilai probability sebesar 0,029 . Nilai thitung $(2,177)>t_{\text {tabel }}(1,967)$ maka pada $\alpha=5 \%$ diputuskan untuk menolak Ho dan menerima Ha. Berdasarkan hal tersebut dapat disimpulkan bahwa kualitas audit berpengaruh signifikan terhadap asimetri informasi. Temuan ini mencerminkan bahwa tenur perikatan audit yang panjang dapat meningkatkan asimetri informasipada perusahaan manufaktur yang terdaftar di BEI. Hal tersebut dikarenakan lamanya tenur akan mempengaruhi independensi auditor dan kualitas audit yang dihasilkan.

\section{Pengaruh Pengungkapan Sukarela, Kualitas Audit Dan Asimetri Informasi} Terhadap Stock Return. Berdasarkan hasil pengujian pada tabel 3diketahui bahwa pengungkapan sukarela, kualitas auditdan asimetri informasi secara simultan memberikan kontribusi sebesar $15,9 \%$ terhadap stock return. Sisanya sebesar $84,1 \%$ merupakan kontribusi faktor-faktor lain (dapat berupa faktor internal maupun eksternal perusahaan) diluar penelitian ini.Secara visual diagram jalur pengaruhpengungkapan sukarela, kualitas audit dan asimetri informasi terhadap stock returndapat ditemukan pada Gambar 4.

Tabel 3. Koefisien jalur pada sub struktur kedua

\begin{tabular}{cccccc}
\hline Path Direction & $\begin{array}{c}\text { Path } \\
\text { Coefficient }\end{array}$ & $t_{\text {hitung }}$ & $\begin{array}{c}t_{\text {tabel }} \\
(\text { db:322) }\end{array}$ & p-value & $\begin{array}{c}R \text { - } \\
\text { Square }\end{array}$ \\
\cline { 1 - 5 } Volunt_Discl $\rightarrow$ Stock_Rtrn & 0.347 & 6.750 & 1.967 & $<0.001$ & 0.159 \\
\cline { 1 - 5 } Audit_Qual $\rightarrow$ Stock_Rtrn & -.091 & -1.777 & 1.967 & 0.076 & \\
\cline { 1 - 5 } Asym_Inf $\rightarrow$ Stock_Rtrn & -.250 & -4.826 & 1.967 & $<0.001$ & \\
\hline
\end{tabular}

Hal tersebut memberikan implikasi bahwaperluperhatian bagi manajemen perusahaan untuk melakukan pengungkapan sukarela dengan efektif, memperhatikan dalam pemilihan kelanjutan auditor untuk memberikan kualitas audit yang baik dan menekan asimetri informasi. Upaya tersebut bertujuan guna memberikan stock return yang diharapkan investors.

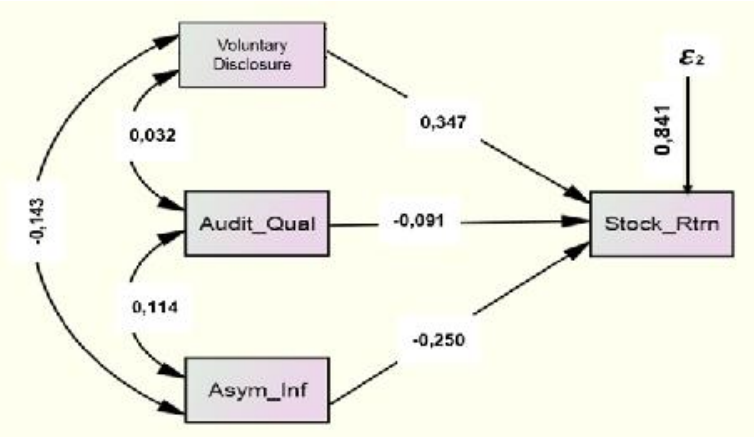

Gambar 4. Model diagram hipotesis 2: pengaruh pengungkapan sukarela, kualitas audit dan asimetri informasi terhadap stock return 
Pengaruh Pengungkapan Sukarela terhadap Stock Return. Hipotesis yang dibangun untuk ini adalah:

$$
\begin{array}{ll}
\mathrm{H}_{0}: \rho Z X_{1}=0 & \begin{array}{l}
\text { Pengungkapan sukarela tidak berpengaruh terhadap stock } \\
\text { return. }
\end{array} \\
\mathrm{H}_{\mathrm{a}}: \rho \mathrm{ZX} \mathrm{X}_{1} \neq 0 & \text { Pengungkapan sukarela berpengaruh terhadap stock return. }
\end{array}
$$

Berdasarkan hasil pengujian pada Tabel3 dapat dilihat nilai thitung pengungkapan sukarela terhadap stock return sebesar 6,750 dengan arah koefisien jalur positif, nilai probability $<0,001$. Nilai thitung $(6,750)>t_{\text {tabel }}(1,967)$, maka pada $\alpha=5 \%$ diputuskan untuk menerima Ha dan menolakHo. Dapat disimpulkan bahwa pengungkapan sukarela berpengaruh signifikan terhadap stock return pada perusahaan industri manufaktur yang terdaftar di BEI. Peningkatan pengungkapan sukarela akan meningkatkan kepercayaan dan ketertarikan investor akan saham perusahaan, sehingga menaikkan harga dan stock return.

Pengaruh Kualitas Audit Terhadap Stock Return. Hipotesis yang dibangun untuk ini adalah:

$\mathrm{H}_{0}: \rho \mathrm{ZX}_{2}=0 \quad$ Kualitas audit tidak berpengaruh terhadap stock return.

$\mathrm{H}_{\mathrm{a}}: \rho Z \mathrm{X}_{2} \neq 0 \quad$ Kualitas audit berpengaruh terhadap stock return.

Berdasarkan hasil pengujian pada Tabel3 dapat dilihat nilai thitung kualitas audit terhadap stock return sebesar -1,777 dengan koefisien jalur negatif, nilai probability sebesar 0,076. Nilai negatif pada thitungmenunjukkan arah koefisien, yang sesuai dengan arah jalurnya. Nilai thitung $(1,777)<t_{\text {tabel }}(1,967)$ maka pada $\alpha=5 \%$ diputuskan untuk menerima Ho dan menolak Ha. Dengan demikian dapat disimpulkan bahwa kualitas audit tidak berpengaruh signifikan terhadap stock return pada perusahaan industri manufaktur yang terdaftar di Bursa Efek Indonesia. Peningkatan pada semakin lama perikatan audit sebagai proxy dari kualitas audit secara signifikan tidak berpengaruh pada peningkatan stock return perusahaan manufaktur yang terdaftar di BEI.

Pengaruh Asimetri Informasi terhadap Stock Return. Hipotesis yang dibangun untuk ini adalah:

$\mathrm{H}_{0}: \rho \mathrm{ZY}=0 \quad$ Asimetri informasi tidak berpengaruh terhadap stock return.

$\mathrm{H}_{\mathrm{a}}: \rho \mathrm{ZY} \neq 0 \quad$ Asimetri informasi berpengaruh terhadap stock return.

Berdasarkan hasil pengujian pada Tabel3 dapat dilihat nilai $t_{\text {hitung }}$ asimetri informasi terhadap stock return sebesar -4,826 dengan koefisien jalur negatif, nilai probability $<0,001$. Nilai negatif pada thitungmenunjukkan arah koefisien, yang sesuai dengan arah jalurnya. Nilai thitung $(4,826)>t_{\text {tabel }}(1,967)$ maka pada $\alpha=5 \%$ diputuskan untuk menolak Ho dan menerima Ha. Berdasarkan hal tersebut dapat disimpulkan bahwa asimetri informasi berpengaruh signifikan terhadap stock return.

Pengujian Kemampuan Asimetri Informasi Sebagai Variabel Pemediasi Atas Pengaruh Pengungkapan Sukarela dan Kualitas Audit Terhadap Stock Return. Pada pengujian kelayakan suatu variabel untuk diuji sebagai variabel pemediasi maka variabel eksogen harus terlebih dahulu memiliki hubungan dengan variabel pemediasi, sehingga memungkinkan variabel tersebut dapat memediasi pengaruh antar dua variabel (Baron and Kenny, 1986).

Pada Gambar 4 menunjukkan bahwa terdapat korelasi antar variabel eksogen dengan variabel pemediasi. Adapun besarnya korelasi masing-masing adalah -0,143 untuk korelasi antara pengungkapan sukarela dengan asimetri informasi. 0,114 korelasi antara 
kualitas audit dengan asimetri informasi. Berdasarkan kriteria tersebut maka pengujian variabel asimetri informasi dapat dikatakan layak untuk dilanjutkan pengujiannya sebagai variabel pemediasi.

Pengujian pengaruh tidak langsung dalam penelitian ini menggunakan Sobel test. Adapun yang menjadi kriteria pengujian untuk Sobel adalah: jika $t_{\text {hitung }}>t_{\text {kritis }}(1,96)$ maka Ho ditolak, jika sebaliknya maka Ha ditolak (Kline, 2010).

Pengujian Kemampuan Asimetri Informasi Sebagai Variabel Pemediasi Atas Pengaruh Pengungkapan Sukarela terhadap Stock Return. Untuk menguji pengaruh tidak langsung pengungkapan sukarela terhadap stock return melalui asimetri informasi digunakan hipotesis sebagai berikut.

$$
\begin{aligned}
\mathrm{H}_{0}: \mathrm{P}_{\mathrm{YX} 1} \times \mathrm{P}_{\mathrm{ZY}}=0 \quad & \begin{array}{l}
\text { Secara tidak langsung melalui asimetri informasi, } \\
\text { pengungkapan sukarela tidak berpengaruh terhadap }
\end{array} \\
& \text { stock return. }
\end{aligned}
$$

Ha : $\mathrm{P}_{\mathrm{YX} 1} \times \mathrm{P}_{\mathrm{ZY}} \neq 0 \quad$ Secara tidak langsung melalui asimetri informasi, pengungkapan sukarela berpengaruh terhadap stock return.

Tabel 4. Hasil ujipengaruh pengungkapan sukarela terhadap stock returnmelalui asimetri

\begin{tabular}{ccccc}
\multicolumn{5}{c}{ informasi } \\
\hline$t_{\text {count }}$ & p-value & $t_{\text {table }}$ & Ho & $H a$ \\
\hline 2,348 & 0,018 & 1,967 & Rejected & accepted \\
\hline
\end{tabular}

Berdasarkan hasil pengujian pada Tabel 4 diperoleh nilai $t_{\text {hitung }}$ pengaruh tidak langsung pengungkapan sukarela $(2,348)>t_{\text {rritis }}(1,967)$. Pada $\alpha=5 \%$ diputuskan untuk menolak Ho dan menerima Ha. Berdasarkan hasil pengujian disimpulkan bahwaasimetri informasisecara signifikan dapat memediasi pengaruh pengungkapan sukarela terhadap stock return.Hal tersebut mengimplikasikan bahwa semakin banyak informasi yang yang diungkapkan akan menurunkan tingkat asimetri informasisehingga meningkatkan harga saham, yang berarti akan meningkatkan stock return.

\section{Pengujian Kemampuan Asimetri Informasi Sebagai Variabel Pemediasi Atas} Pengaruh Kualitas Audir terhadap Stock Return. Untuk menguji pengaruh tidak langsung kualitas auditterhadap stock return melalui asimetri informasi digunakan hipotesis sebagai berikut.

$$
\begin{array}{ll}
\mathrm{H}_{0}: \mathrm{P}_{\mathrm{YX} 2} \times \mathrm{P}_{\mathrm{ZY}}=0 & \begin{array}{l}
\text { Secara tidak langsung melalui asimetri informasi, } \\
\text { kualitas audit tidak berpengaruh terhadap stock return. }
\end{array} \\
\mathrm{Ha}: \mathrm{P}_{\mathrm{YX} 2} \times \mathrm{P}_{\mathrm{ZY}} \neq 0 & \begin{array}{l}
\text { Secara tidak langsung melalui asimetri informasi, } \\
\text { kualitas audit berpengaruh terhadap stock return. }
\end{array}
\end{array}
$$

Tabel 5. Hasil ujipengaruh kualitas audit terhadap stock returnmelalui asimetri informasi

\begin{tabular}{ccccc}
\hline$t_{\text {count }}$ & $p$-value & $t_{\text {table }}$ & Ho & $H a$ \\
\hline$-1,984$ & 0,047 & 1,967 & Rejected & accepted \\
\hline
\end{tabular}

Berdasarkan hasil pengujian pada Tabel 5 diperoleh nilai thitung pengaruh tidak langsung kualitas audit $(1,984)>t_{\text {kritis }}(1,967)$, nilai negatif pada $t_{\text {hitungmenunjukkan arah }}$ jalur hubungannya. Pada $\alpha=5 \%$ diputuskan untuk menolak Ho dan menerima Ha. 
Berdasarkan hasil pengujian disimpulkan bahwaasimetri informasisecara signifikan dapat memediasi pengaruh kualitas audit terhadap stock return. Pada saat kualitas audit secara langsung tidak berpengaruh signifikan terhadap stock return, maka keberadaan asimetri informasidapat memediasi pengaruh dari kualitas audit terhadap stock return. Hal tersebut mengimplikasikan bahwa kualitas audit yang baik akan menurunkan asimetri informasisehingga meningkatkan volume transaksi saham dan meningkatkan harga saham, selanjutnya akan meningkatkan stock return.

\section{PENUTUP}

Pengungkapan menjadi satu kunci penting dalam upaya menekan asimetri informasi. Pengungkapan sukarela tidak bisa dipandang hanya dari sisi jumlah informasi yang diungkapkan, tetapi relevansi dan kualitas informasi menjadi hal lebih penting sehingga para pengguna informasi dapat memanfaatkan informasi tersebut untuk pengambilan keputusan mereka.

Temuan ini menunjukkan bahwa lamanya masa perikatan audit diduga berpotensi memperlemah tingkat independensi auditor, berlanjut pada menurunnya kualitas audit. Kualitas audit yang demikian selanjutnya dapat meningkatkan asimetri informasi pada perusahaan manufaktur yang terdaftar di BEI.Dalam hal ini, independensi auditor dipandang sangat penting dalam upaya pengungkapan informasi keuangan yang sesungguhnya, relevan dan berkualitas, sehingga kualitas audit diharapkan tetap terjaga baik untuk memperkecil asimetri informasi.

Kecukupan dan kualitas informasi yang diterima oleh investor melalui pengungkapan sukarela memiliki pengaruh pada perilaku investor dalam mengambil keputusan investasinya. Peningkatan pengungkapan sukarela akan meningkatkan kepercayaan dan ketertarikan investor akan saham perusahaan. Semakin banyak informasi relevan yang diungkapkan, maka dipandang investor akan memperkecil risiko investasi, karena ketidakpastian informasi semakin dimitigasi, sehingga meningkatkan volume transaksi dan meningkatkan stock return.

Kualitas audit secara langsung tidak berpengaruh signifikan terhadap stock return pada perusahaan industri manufaktur yang terdaftar di Bursa Efek Indonesia. Peningkatan semakin lama perikatan audit sebagai proxy dari kualitas audit secara signifikan tidak berpengaruh pada peningkatan stock return perusahaan manufaktur yang terdaftar di BEI. Hal tersebut diduga terjadi karena para investor dan calon investor belum melihat bahwa audit tenur dapat secara langsung menjadi pertimbangan utama dalam melakukan keputusan jual beli investasinya atas sahamnya. Dugaan lain sebagai penyebab mengapa kualitas audit (yang diproxikan dengan audit tenure)tidak berpengaruh secara langsung terhadap stock return adalah bahwa perusahaan manufaktur yang diamati dalam penelitian ini tidak menggunakan industry-specialist auditor.

Penurunan asimetri informasiakan maningkatkan kepercayaan investor akan perusahaan dan akan meningkatkan volume transaksi saham,selanjutnya meningkatkan stock returnperusahaan industri manufaktur yang terdaftar di BEI. Kondisi rendahnya asimetri informasiseperti ini dipandang memberi efek yang menguntungkan principals dan juga calon investor saham perusahaan, karena mereka menggunakan informasi dengan kualitas yang lebih baik, dengan risiko investasi yang rendah dalam membuat keputusan investasinya. 
Semakin banyak informasi perusahaan diungkapkan, akan mengurangi ketidakpastian informasi perusahaan, asimetri informasi semakin rendah dan semakin kecil perkiraan risiko investasi, semakin menarik perhatian para investor dalam melakukan kegiatan investasinya. Kedaan ini akan meningkatkan volume transaksi dan harga saham dan meningkatkan return investasi saham yang bersangkutan, sehingga asimetri informasi dapat memediasi pengaruh dari pengungkapan sukarela terhadap stock return.

Pada saat kualitas audit secara langsung tidak berpengaruh signifikan terhadap stock return, maka keberadaan asimetri informasidapat memediasi pengaruh dari kualitas audit terhadap stock return. Hal tersebut mengimplikasikan bahwa kualitas audit yang baik akan menurunkan asimetri informasisehingga meningkatkan volume transaksi saham dan meningkatkan harga saham, selanjutnya akan meningkatkan stock return.

\section{DAFTAR RUJUKAN}

Aboody, D., and Lev, B. (2000) "Information Asymmetry, R\&D, and Insider Gains". The Journal of Finance, 55, 2747-2766.

Aljifri, K. (2008) Annual Report Disclosure in A Developing Country: The Case of the UAE. Advances in Accounting, Incorporating Advances in International Accounting, 24, 93-100.

Al-Thuneibat, A. A., Al Issa, R. T.I., and Baker, R.A.A. (2010) "Do Audit Tenure and Firm Size Contribute To Audit Quality? Empirical Evidence from Jordan". Managerial Auditing Journal, 26 (4), Emerald Group Publishing Limited. DOI 10.1108/02686901111124648.

Attig, N., Fong, W.M., Gadhoum, Y. and Lang, L. (2006) "Effects of Large Shareholding On Information Asymmetry and Stockliquidity". Journal of Banking \& Finance.Vol.30.

Balsam, S. (2002) "Accrual Management, Investor Sophisticated, and Equity Valuation: Evidence from 10-Q Fillings". Journal of Accounting Research, 40 (4), 987-1012.

Banghoj, J. and Plenborg, T. (2008) "Value Relevance of Voluntary Disclosure in The Annual Report". Journal of Accounting and Finance, Vol. 48.

Baron, R.M. \& Kenny, D.A. (1986) "The Moderator-Mediator Variable Distinction in Social Psychological Research: Conceptual, Strategic and Statistical Considerations". Journal of Personality and Social Psychology. 51 (6). American Psychologycal Association.

Bernardi, R.A. (2009) Establishing a Baseline for Assessing the Frequency of Auditors' Comments Concerning Perceived Client Integrity. Managerial Auditing Journal, 24 (1), $4-21$.

Botosan, C. A., and Plumlee, M. A. (2002) "A Reexamination of Disclosure Level and Expected Cost Of Equity Capital”. Journal of Accounting Research, 40, 21-40. http://dx.doi.org/10.1111/1475-679X.00037.

Bravo, F. (2015) Forward-Looking Disclosure and Corporate Reputation as Mechanisms to Reduce Stock Return Volatility. Revista de Contabilidad-Spanish Accounting Review, http://dx.doi.org/10.1016/ j.rcsar.2015.03.001 1138-4891/C 2015 ASEPUC. Published $b$ y elsevier.es

Brown, S., and Hillegeist, S. A. (2007) How Disclosure Quality Affects the Level of Information Asymmetry. Review of Accounting Study, 12:443-477, Springer Science 
Business Media, LLC. Department of Accounting, Goizueta Business School, Emory University, Atlanta, GA, USA.

Bruslerie, H., and Gabteni, H. (2010) Voluntary Financial Disclosure, Introduction of IFRS and the Setting of A Communication Policy: An Empirical Test on SBF French Firms Using a Publication Score. Multinational Financial Society, Barcelona: Espagne.

Buskirk, A.V. (2011) Disclosure Frequency and Information Asymmetry. Review of Quantitative Financial Accounting (2012) 38:411-440. Springer Science+Business Media, LLC. Fisher College of Business, Ohio State University, 2100 Neil Avenue, Columbus, $\mathrm{OH} 43210$, USA.

Carey, P. and Simnett, R. (2006) Audit Partner Tenure and Audit Quality. The Accounting Review 81, 2006.

Choi, J.J., Kho, S.B., Xiu, L., and Simunic, D. (2008) Audit Big 4 Premiums, Legal Liability Regimes, and Return: Theory and Cross-Country Evidence. Contemporary Accounting Research. Vol. 25.

Clinch, G, Stokes, D.and Zhu, T. (2012) Audit Quality and Information Asymmetry between Traders. Accounting and Finance. 52, 743-765.

Daniri, M.A. (2006) Good Corporate Governance: Konsep dan penerapannya dalam konteks Indonesia. Edisi ke-2. Ray Indonesia.

Darmadi, S. (2013) Corporate Governance Disclosure In The Annual Report: An Exploratory Study on Indonesian Islamic banks. Humanomics, 29 (1). Emerald Group Publishing Limited. DOI 10.1108/08288661311299295.

Dunn, K. A., and Mayhew, B. W. (2004) Audit Firm Industry Specialization and Client Disclosure Quality. Review of Accounting Studies, Vol. 9.

Easley, D., and O'Hara, M. (2004) Information and the cost of capital. The Journal of Finance, Vol. 59.

Ertimur, Y. (2007) Discussion of How Disclosure Quality Affects the Level of Information Asymmetry. Review of Accounting Study (2007) 12:479-485. Springer Science+Business Media, LLC. The Fuqua School of Business, Duke University, 1 Towerview Drive, Durham, NC 27708, USA.

Favere-Marchesi, M. (2000) Audit Quality in ASEAN. International Journal of Accounting. vol. 35, no. 1. Accounting and Regulatory Issues. Association for Investment Management and Research.

Fishman, M. J., and Hagerty, K. M. (1989) "Disclosure Decisions by Firms and the Competition for Price Efficiency". Journal of Finance, Vol. 44.

Gajewski, J. F., and Li li. (2015) Can Internet-Based Disclosure Reduce Information Asymmetry. Advances in Accounting, Incorporating Advances in International Accounting.

Ghozali, I. (2012) Aplikasi Analisis Multivariate Dengan Program IBM SPSS 20, Edisi Enam. Semarang: Universitas Diponegoro.

Goto, S., Watanabe, M. and Xu, Y. (2009) Strategic Disclosure and Stock Returns: Theory and Evidence from US Cross-Listing. The Review of Financial Studies /v 22 n 42009.

Gregory, M.F., Bosch, F.A.J.V., and Henk, V. (2004) "The Importance of Disclosure in Corporate Governance Self-regulation Across Europe: A Review of the Winter Report and the EU Action Plan". International Journal of Disclosure and Governance; Mar , 1 (2). 
Griffin, P., Lont, D., and Sun, Y. (2008) "Corporate Governance and Audit Fees: Evidence of Counter Vailing Relations". Journal of Contemporary Accounting and Economics, 4 (1), 18-49. http://dx.doi.org/ 10.1016/S1815-5669(10)70028-X.

Gul, F. A., Kim, J. B. and Qiu, A. A. (2010) "Ownership Concentration, Foreign Shareholding, Audit Quality, and Stock Price Synchronicity: Evidence from China”. Journal of Financial Economic, Vol. 95.

Haggard, K.S., Martin, X.M. and Pereira, R. (2008) "Does voluntary disclosure improve stock price informativeness?." Financial Management, 37 (4).

Hakim, F. and Omri, M.A.. (2010) "Quality of the External Auditor, Information Asymmetry, and Bid-Ask Spread". International Journal of Accounting and Information Management, 18 (1), 5-18.

Ikatan Akuntan Indonesia, Dewan Standar Akuntansi Keuangan, (2013) PSAK (Pernyataan Standar Akuntansi Keuangan), Jln. Sindang Laya No.1 Jakarta.

Indonesian Capital Market Electronic Library-ICAMEL, visited from: http://www.idx.co.id/en-us/home/aboutus/idxprogram/educationalprogram.asp x, 24 September 2016, at 21:05 wib.

http://www.idx.co.id/en-us/home/listedcompanies/listedcompanycalendar. aspx, 24 September 2016, at 21:18 wib.

http://www.idx.co.id/en-us/home/listedcompanies/announcement.aspx,

visited from: September 2016, at 21:43 wib.

Ismail, T.H. and El-Shaib, N.M. (2012) "Impact of Market And Organizational Determinants On Voluntary Disclosure In Egyptian Companies". Meditari Accountancy Journal and Research. 20 (2), Emerald Group Publishing Limited.

Kline, R.B., (2010) Principles and Practice of Structural Equation Modeling. $3^{\text {rd }}$ edition. the Guilford Press. New York London.

Kong, D., Xiao, T. and Liu, S. (2011) Asymmetric Information, Frm Investment and Stock Prices. China Finance Review International, 1 (1), 6-33.

Leuz, C., and Verrecchia, R. E. (2000) "The Economic Consequences of Increased Disclosure". Journal of Accounting Research, 38, 91-124.

Lobo, G.J., and Zhou, J. (2001) "Disclosure Quantity and Earning Management". Asia Pacific Journal Of Accounting And Economics. Vol. 12, March 1002. Hong Kong.

Manurung, Adler H. (2013) Teori Investasi: Konsep dan Empiris. PT. Adler Manurung Press. Jakarta.

Muhamad, R., Shahimi, S., Yahya, Y. and Mahzan, N. (2009) Disclosure Quality on Governance Issues in Annual Reports of Malaysian PLCs. International Business Research. 2 (4).

Muller, K. A., and Riedl, E. J. (2002) External Monitoring of Property Appraisal Estimates and Information Asymmetry. Journal of Accounting Research, 40 (3), 865-881.

Murphy, M.L. (2014) Improving Audit Quality: An Interview with Cynthia M. Fornelli, an Executive Director of the Center for Audit Quality. The CPA Journal, February.

Nakhodchari, F. S., and Garkaz, M. (2014) "Correlation Between Ownership Concentration, Disclosure, And Information Asymmetry In Companies Listed On The Stock Exchange'. Kuwait Chapter of Arabian Journal of Business and Management, 4 (1), September. 
Nikolaou, I.E., Chymis, A., and Evangelinos, K. (2013) Environmental Information, Asymmetric Information, and Financial Markets: A Game-Theoretic Approach. Environ Model Assess. Springer Science+Business Media Dordrecht .

Nosheen, S. (2013) "Impact of Board Leadership and Audit Quality on Disclosure Quality: Evidence from Pakistan". International Journal of Disclosure and Governance. 10 (4), Macmillan Publishers Ltd.

Nuryaman. (2012) “The Influence of Corporate Governance Practice on The Company's Financial Performance". Journal of Global Business and Economic, Global Research.Com ISSN 2180-3625. 5 (1), July.

(2013) "The Influence of Earnings Management on Stock Return and the Role of Audit Quality as a Moderating Variable". International Journal of Trade, Economics and Finance, 4 (2), April.

Otoritas Jasa Keuangan. (2014) Roadmap Tata Kelola Perusahaan Indonesia, Untuk Menuju Tata Kelola Emiten dan Perusahaan Publik yang Baik.

Otoritas Jasa Keuangan, Surat Edaran Otoritas Jasa Keuangan Nomor 32 /SEOJK.04/2015 Tentang Pedoman Tata Kelola Perusahaan Terbuka.

Ramli, I., Agoes, S., and Setyawan, I. R. (2016) "Information Asymmetry and The Role Of Foreign Investors In Daily Transactions During The Crisis; A Study Of Herding In The Indonesian Stock Exchange". The Journal of Applied Business Research. January/February 2016 Volume 32, Number 1.

Riduwan and Kuncoro, M. (2011) Cara Menggunakan dan Memaknai Analisis Jalur. Bandung: Alfabeta.

Ross, S., Westerfield, R., Jaffe, J., andJordan, B. (2015) Corporate Finance. $11^{\text {th }}$ edition. McGraw-Hill Education.

Sekaran, U., and Bougie, R. (2010) Research Methods for Business. A Skill-Building Approach. Fifth edition. John Wiley \& Sons, Inc., Ltd. Publication, United Kingdom.

Silveira, A.D.M.D. and Barros, L.A.B.D.C. (2006) "Correlate Governance Quality and Firm Value in Brazil". Journal of Financial Economics. at: http://ssrn.com/abstract $=923310$

Taplin, R., Tower, G., and Hancock, P. (2002) Disclosure (discernibility) and Compliance of Accounting Policies: Asia-Pacific Evidence. Accounting Forum, 26 (2).

Varici, I. (2013) The Relationship between Information Asymmetry and the Quality of Audit: An Empirical Study in Istanbul Stock Exchange. International Business Research; 6 (10).

Venkatachalam, M. (2015) "Discussion of Corporate Disclosure Practices, Institutional Investors, and Stock Return Volatility". Journal of Accounting Research, Vol. 38, Supplement: Studies on Accounting Information and the Economics of the Firm. Published by: Wiley.

Von-Alberti, A.L., Hutaibat, K., and Al-Htaybat. (2012) "Mapping Corporate Disclosure Theories". Journal of Financial Reportiing and Accounting. 10 (1).

Yassin, M.M., Ali, H.Y. and Hamdallah, M.E. (2015) "The Relationship Between Information Asymmetry and Stock Return in the Presence of Accounting Conservatism". International Journal of Business and Management. 10 (5). 